\title{
Alocação de reserva legal em propriedades rurais: Do cartesiano ao holístico
}

\author{
Hevandro C. Delalibera ${ }^{1}$, Pedro H. Weirich Neto ${ }^{1}$, Angelo R. C. Lopes ${ }^{1}$ \& Carlos H. Rocha ${ }^{1}$
}

\begin{abstract}
RESUMO
Ao exigir áreas de Preservação Permanente (APP) e Reserva Legal (RL) em todos os imóveis rurais do Brasil, o Código Florestal Brasileiro (Lei Federal 4771/1965) se reverte em um dos instrumentos mais importantes com o propósito de mitigar impactos ambientais das atividades agrícolas. Como em outros estados, no Paraná esta legislação também foi ignorada; para cumprir o disposto no Código Florestal e estipular prazo para as adequações necessárias, foi instituído o Sistema de Manutenção, Recuperação e Proteção da Reserva Legal e Áreas de Preservação Permanente - SISLEG (Decreto Estadual 387/1999). Com o objetivo de se analisar essas normativas, elaborou-se um estudo de imóvel rural típico dos Campos Gerais do Paraná e, com base em técnicas de sensoriamento remoto, se definiram as APPs e o montante necessário para compor a RL. Como a legislação não especifica critérios objetivos para a localização das RLs, duas perspectivas foram avaliadas: a maximização do potencial agrícola da propriedade e a conservação da natureza, com base no contexto ambiental e hidrográfico no qual o imóvel está inserido. Conclui-se que a legislação pode contribuir para mitigar impactos não contemplando, porém, conceitos importantes para o planejamento territorial e conservação da natureza.
\end{abstract}

Palavras-chave: código florestal, área de preservação permanente, SISLEG, geoprocessamento

\section{Legal reserve allocation in rural properties: From the cartesian to the holistic}

\begin{abstract}
The Brazilian Forest Code (Federal Law 4771/1965), by defining Permanent Protection Areas (PPA) and Legal Reserves (LR) on every rural property in the country, is one of the most important measures to mitigate environmental impacts from farming activities. As in many other states, such legislation has been disregarded in Paraná. To comply with Forest Code requirements and define time limits for its accomplishment, the State of Paraná has enacted the System for Maintenance, Recovery and Protection for the Legal Reserve and Permanent Protection Areas - SISLEG (State Decree 3320/2004). This paper analises the accomplishment of this system in a typical farmstead in the Campos Gerais of Paraná. Based on remote sensing techniques, PPAs were mapped and the total area for LR composition defined. As the legislation does not clearly define places for the location of LRs, two perspectives were approached: the maximization of the farming potential of the property and of nature conservation, based on the environmental and hydrographic context in which the farm is embedded. It is concluded that the law can contribute to mitigate some impacts, but it does not, however, contemplate important concepts for territorial planning and nature conservation.
\end{abstract}

Key words: forest code, permanent protection areas, SISLEG, geoprocessing 


\section{INTRODUÇÃO}

Ao longo de sua evolução, a humanidade tem buscado reconhecer, testar e modificar o ambiente em que vive, com o objetivo principal de maximizar a exploração dos recursos naturais, situação que vem provocando degradação no seu potencial de renovação. Em função da vasta superfície territorial, o Brasil tem sido exemplo neste contexto, visto que a cada ano se faz opção pela abertura de novas fronteiras agrícolas, com o intuito de aumentar a produção. O processo de abertura de novas áreas, no entanto, vem ocorrendo de maneira rápida e dissociada de estratégias de planejamento territorial, ocasionando danos de difícil reparação aos ecossistemas naturais.

Muitas dessas fronteiras agrícolas, por serem áreas frágeis, requerem uma série de precauções e medidas que visem ao desenvolvimento sustentável, em que a exploração econômica desses ambientes se deve proceder dentro dos limites de capacidade de suporte dos ecossistemas, permitindo a renovação dos recursos (Marouelli, 2003). Sendo assim, é de relevante importância a implementação de meios corretos de exploração agrícola e de manejo dos recursos naturais (Paccagnella \& Senô, 2003).

A bacia hidrográfica é apontada como a unidade geográfica ideal para o planejamento integrado do manejo dos recursos naturais (Brasil, 1987; Odum, 1988). A concepção de planejamento econômico e social, que deriva do planejamento físico territorial, é um ideal aspirado pelos planejadores. Quando se trata de uma propriedade agrícola, no entanto, os trabalhos de planejamento tendem a ser isolados do contexto ambiental e hidrográfico onde estão inseridos.

No Brasil, outro instrumento jurídico significativo para a regulamentação de uso e proteção da flora e da fauna, é o chamado Código Florestal, instituído pela Lei Federal $n^{\circ} 4.771$ de 1965 . Florestas e outras formações da vegetação são declaradas de interesse comum, definindo-se limites para o uso privativo desses recursos; deste modo são definidas, neste regimento, normativas em relação às Áreas de Preservação Permanente (APP) e de Reserva Florestal Legal (RL) (Brasil, 1965).

Conforme definido no Artigo $1^{\circ}$, $\S 2^{\circ}$, Inciso II, do Código Florestal, as APPs são áreas protegidas, cobertas por vegetação nativa, com a função ambiental de preservar os recursos hídricos, a paisagem, a estabilidade geológica, a biodiversidade, o fluxo gênico de fauna e flora, a proteção do solo e assegurar o bem-estar das populações humanas (Brasil, 1965). As APPs atuam principalmente no equilíbrio do regime hidrológico, promovendo a estabilização das linhas de drenagem natural e suas áreas marginais. Em paisagens agrícolas, as APPs funcionam como filtros biológicos nos processos de erosão laminar, lixiviação, deriva e fluxo lateral de agroquímicos e ainda possuem a função de isolamento e quebra-ventos para essas áreas (Valente \& Gomes, 2005).

No artigo $2^{\circ}$ do Código Florestal são definidas, como de preservação permanente, as áreas situadas: a) ao longo dos cursos d’água, devendo ser respeitada uma faixa mínima em função da largura do rio desde o seu nível mais elevado; b) ao redor de lagoas, lagos ou reservatórios naturais e artificiais; c) nas nascentes e olhos d'água; d) no topo de morros, montes, montanhas e serras; e) nas encostas com inclinação superior a 45 graus (Brasil, 1965).

Outra forma de unidade de conservação especificada no Artigo $1^{\circ}$, $\S 2^{\circ}$, Inciso III do Código Florestal, são as áreas de Reserva Legal (RL), definidas como a área localizada no interior de uma propriedade rural, excetuando-se as APPs, necessárias ao uso sustentável dos recursos naturais, à conservação e à reabilitação dos processos ecológicos, à conservação da biodiversidade e ao abrigo e proteção de fauna e flora nativas; assim, com exceção da região compreendida pela floresta Amazônica e o bioma Cerrado, a título de RL, devem ser mantidos cobertos por vegetação natural no mínimo $20 \%$ da propriedade rural.

Nas áreas de exploração agrícola as RLs favorecem o controle natural de pragas pela manutenção de maior diversidade de habitats e atuam como barreiras na disseminação de doenças. Contribuem, também, para melhor disponibilidade hídrica e na retenção de umidade, reduzindo os efeitos provocados por estiagens (Valente \& Gomes, 2005). O manejo das RLs também é restringido pela legislação, contemplando somente coleta e corte seletivo.

A ocupação territorial do Paraná, embora recente em relação a outros estados do Brasil, provocou uma redução extrema de sua cobertura vegetal natural. Segundo a Secretaria Estadual do Meio Ambiente - SEMA (1996) restavam aproximadamente 8,8\% da cobertura original. As únicas áreas remanescentes de vegetação natural expressivas estão restritas às porções com altitudes elevadas da Serra do Mar, no litoral norte do estado e no Parque Nacional do Iguaçu; as demais áreas de vegetação remanescente correspondem a fragmentos isolados, em tamanhos e estágios de sucessão ecológica diversos, localizadas principalmente na região centro-sul e nas áreas escarpadas que separam os planaltos estruturais do estado.

Com base em tal situação foi instituído, através do Decreto Estadual 387/1999 (Paraná, 1999), o Sistema de Manutenção, Recuperação e Proteção da Reserva Legal e Áreas de Preservação Permanente (SISLEG). Esta legislação surgiu em decorrência de um apelo do setor agrícola do Paraná que teve, em 1998, centenas de agricultores acionados judicialmente pelo não cumprimento das determinações do Código Florestal. Este decreto estabeleceu prazo até 2018 para que as propriedades rurais estejam em dia com a situação ambiental. Esta legislação é referência para outros estados e para o Governo Federal (IAP, 2005).

O SISLEG ainda estabelece zonas prioritárias para a conservação e recuperação no Estado, através da formação de corredores de biodiversidade. Os corredores de biodiversidade, conforme definido no artigo $4^{\circ}$ do Decreto 387/1999, são faixas situadas ao longo dos principais rios e afluentes das diversas bacias hidrográficas do Estado (Paraná 2004a), com a função de assegurar a conectividade das áreas naturais e o fluxo gênico da biodiversidade.

Outros critérios, normas, procedimentos e conceitos complementares foram aprovados em 2004, pelo Decreto 3.320/2004 (Paraná 2004a). Através da Portaria 233/2004, 
do Instituto Ambiental do Paraná - IAP (gestora do SISLEG), foram definidos os mecanismos para operacionalização do SISLEG no estado (Paraná 2004b).

Conforme definido no decreto 3.320/2004 (Paraná, 2004a), as RLs podem estar alocadas no próprio imóvel ou podem ser compensadas, em regime de servidão florestal em imóvel de terceiros, desde que seja respeitada a Portaria IAP 233/2004 (Paraná 2004b).

A APP também poderá ser computada no cálculo da composição da RL, desde que não implique em conversão de novas áreas para uso alternativo do solo, quando a soma da APP e RL exceder a $25 \%$ da pequena propriedade agrícola (menor ou igual a 30 hectares), e 50\% nas demais, conforme o artigo 16, $\S 6^{\circ}$ do Código Florestal (Brasil, 1965). Destaca-se também que a RL, após averbada, poderá ser declarada Reserva Particular do Patrimônio Natural - RPPN.

Neste âmbito, a definição de áreas destinadas a RL através do SISLEG tem sido, via de regra, realizada com base em parâmetros internos à propriedade rural, em particular aspectos relativos ao potencial agrícola das terras, de modo a minimizar perdas no potencial produtivo e econômico da propriedade.

Desta forma, o objetivo deste trabalho foi analisar a adequação do uso do solo às exigências do SISLEG referentes à alocação da Reserva Legal em uma propriedade rural, típica do contexto agrícola regional, através de duas abordagens distintas: uma priorizando a aptidão agrícola das terras e, na outra, o contexto ambiental e hidrográfico onde a propriedade se insere, de modo a planejar a conectividade entre áreas potenciais para a conservação.

\section{MATERIAL E MÉTODOS}

A área de estudo consiste na unidade de produção agrícola denominada Taquaruçu, localizada no município de Ponta Grossa, PR, com coordenadas geográficas da sede em $25^{\circ} 01^{\prime} 25^{\prime}$ ' de latitude Sul e $50^{\circ} 18^{\prime} 24^{\prime}$ ' de longitude Oeste. Esta propriedade, com 264,96 ha, está inserida no bioma Mata Atlântica, em região identificada como Área de Tensão Ecológica - Ecótono (IBGE, 2004), entre as formas de vegetação associadas à Floresta Ombrófila Mista (Floresta com Araucária) e as formações campestres associadas a Estepe Gramíneo Lenhosa (Campos Gerais). O limite meridional desta área se situa em altitude próxima a 920 m.s.n.m., ao longo do divisor de águas entre três microbacias afluentes do rio Tibagi, a segunda maior bacia hidrográfica do Paraná.

Para análise da propriedade na escala local e do contexto hidrográfico e ambiental em escala mais ampla, foram utilizadas: a) fotografias aéreas pancromáticas de 1980 (escala 1:25.000); b) cartas topográficas (escala 1:50.000) e c) uma composição de imagens dos satélites IRS - Indian Remote Sensing Satellite (pancromático) com LANDSAT 7 ETM+ (multiespectral) de 2003, com resolução espacial final de $5 \mathrm{~m}$. Esta imagem, previamente georreferenciada, foi utilizada como referencial cartográfico para as etapas subseqüentes. Os dados de uso das terras foram atualizados através de imagens 2005 do satélite Sino-Brasileiro - CBERS II, com resolução espacial de $20 \mathrm{~m}$.

Utilizou-se, no geoprocessamento das imagens, o programa computacional do tipo Sistema de Informações Georreferenciadas (SIG), SPRING ${ }^{\circledR}$ versão 4.1 (Instituto Nacional de Pesquisas Espaciais - INPE). Através da composição IRS + LANDSAT 7 foram georreferenciadas as fotografias aéreas digitalizadas (300 dpi), as imagens do satélite CBERS II e as cartas topográficas; em seguida, geraram-se os mosaicos de fotos aéreas para análise da propriedade rural e de imagens de satélite, para análise das sub-bacias hidrográficas.

A partir dos dados digitais das imagens de satélite, realizaram-se composições espectrais entre as bandas correspondentes ao infravermelho próximo, verde e vermelho (RGB - 423). Esta composição destaca a refletância da cobertura vegetal, favorecendo a interpretação e conseqüente precisão no mapeamento de uso das terras. Também foram empregadas funções de pré-processamento e realce de imagens, disponíveis no programa utilizado para o processamento dos dados, sendo estas os ajustes na intensidade, contraste e brilho da imagem resultante da composição de bandas utilizada. Essas funções são importantes pois possibilitam que determinadas respostas espectrais, relacionadas a particularidades do terreno, sejam realçadas nas diferentes bandas fornecendo, desta forma, subsídios para comparação entre padrões de uso das terras e interpretação visual da resposta espectral dessas imagens.

Com o auxílio de um receptor de sinais de satélites artificiais do sistema GPS (Global Position System), modelo Etrex $^{\circledR}$ (Garmin), as fotografias e imagens impressas, realizaram-se checagens a campo para confirmar a localização de nascentes, córregos e a identificação de áreas propícias à alocação da RL. Também foram interpretadas características dos solos a partir de amostragens com trado pedológico em locais previamente selecionados com base em fotointerpretação e os dados extrapolados para a propriedade, a partir de correlação entre topossequências e classes de solos.

Como interface entre o receptor GNSS (Global Navigator Satellite System) e o computador, utilizou-se o programa computacional GPS TrackMaker ${ }^{\circledR}$ (Odilon Ferreira Junior), possibilitando a manipulação digital dos dados adquiridos.

A análise legal deste trabalho foi fundamentada no Código Florestal Brasileiro (Lei Federal $n^{\circ} 4771$ de 1965) e na Lei Florestal Paranaense (Lei Estadual $n^{\circ} 11.054$ de 1995); além dessas normativas, fundamentou-se também nos Decretos Estaduais no 387 e 3.320 e na Portaria n 233 do Instituto Ambiental do Paraná - IAP, que definem normas e diretrizes operacionais para o SISLEG - Sistema de Manutenção, Recuperação e Proteção da Reserva Legal e Áreas de Preservação Permanente no Estado do Paraná (Brasil, 1965; Paraná, 1995; 1999; 2004a; 2004b).

A partir das isocotas da carta topográfica (eqüidistância entre curvas de nível igual a $20 \mathrm{~m}$ ), gerou-se um modelo clinométrico da área e das sub-bacias hidrográficas utilizando-se como base os limites rígidos sugeridos por Lepsch (1983) entre os intervalos de: 0 a 5\%, 5 a 10\%, 10 a 15\%, 
15 a 45\%, 45 a $70 \%, 70$ a 100\%. Áreas maiores que $100 \%$ de inclinação são definidas como de preservação permanente (APPs). As nascentes e a hidrografia local foram delineadas a partir da base cartográfica e confirmadas com dados obtidos em visitas ao local; a partir de ferramentas específicas do SPRING ${ }^{\circledR}$, foram gerados vetores radiais e paralelos com o objetivo de localizar a vegetação ripária mínima de preservação permanente.

A partir do mapeamento das APPs, realizou-se análise para locação das áreas destinadas à composição da Reserva Legal (RL). Segundo a Lei Florestal Paranaense (Paraná, 1995), para propriedades acima de 50 ha as áreas de Reserva Legal devem ser compostas de formações de vegetação natural, florestais ou campestres. No caso de inexistência de vegetação nativa suficiente no imóvel rural para alocação da RL, o Decreto Estadual 3320/2004 autoriza a sua constituição em área a ser restaurada, conforme intervalos e prazo definidos no Decreto 387/1999 (1/20 por ano até 2018).

Pelo exposto acima, ressalta-se a subjetividade para a interpretação e alocação da RL, podendo ser definida em critérios convenientes ao domínio da propriedade, desde que respeitado o mínimo de $20 \%$ da área total da propriedade.

A primeira visão definida neste trabalho como cartesiana, é limitada à área compreendida pela propriedade rural, com o objetivo da maximização do seu potencial agrícola; a segunda visão, definida como holística, considera o contexto ambiental e hidrográfico no qual a propriedade está inserida.

Na perspectiva definida como cartesiana, propôs-se uma maximização do uso agrícola, direcionando a agricultura empresarial praticada e se empregando conceitos de aptidão agrícola das terras e a otimização da motomecanização; desta forma, sempre que possível, se mantiveram glebas contínuas para minimizar manobras excessivas com o maquinário agrícola nas atividades de cultivo. A partir deste critério, da análise do mapa de declividades e da interpretação das características das classes de solos, alocaram-se as áreas de RL nos locais com menor interesse para as atividades agrícolas.

No enfoque conservacionista para alocação da RL utilizaram-se, como parâmetro, as áreas mapeadas como APP, a análise da cobertura da vegetação nativa da propriedade e a viabilidade de interligação desses remanescentes, através da vegetação ripária com outras áreas remanescentes no contexto das microbacias e a sua interligação com a drenagem principal (bacia hidrográfica do rio Tibagi).

De modo complementar se elaborou a análise morfométrica das microbacias, estudando-se o índice de compacidade $(\mathrm{Kc})$ ou de forma, proposto por Gravelius (Valente \& Gomes, 2005). Este parâmetro define a relação entre o perímetro da microbacia e a circunferência de um círculo de área igual à da microbacia; quanto mais próximo da unidade for o Kc, mais arredondada será a microbacia. Índices muito acima da unidade indicam microbacias estreitas e alongadas, com influência no volume escoado pela microbacia na ocorrência de chuvas torrenciais.

Também se determinou a ordem dos cursos d’água (Oc), utilizando-se a metodologia clássica de Strahler que indica o seu grau de ramificação e a densidade de drenagem (Dd), a qual mostra o comprimento total das linhas de drenagem existentes por quilômetro quadrado de área da microbacia, como indicador da intensidade de dissecação do relevo (Valente \& Gomes, 2005).

\section{RESULTADOS E DISCUSSÃO}

De acordo com o definido pelo Código Florestal e através da interpolação desses dados com o mapeamento de uso das terras para a área de estudos, foram determinados os quantitativos de áreas necessárias para o cumprimento da legislação (Tabela 1). Para contemplar as exigências quanto às Áreas de Preservação Permanente (APPs), relativas à ocorrência de nascentes e de vegetação ciliar, são necessários 36,89 ha (13,9\% da área total da propriedade) dos quais 5,73 ha (15,5\% das APPs) deverão ser recuperados, porém, em vários pontos das APPs mapeadas são encontradas espécies exóticas arbóreas de caráter invasor, particularmente o Pinus spp, que possui um elevado potencial de dispersão e colonização, razão por que é considerado agressivo e prejudicial à vegetação nativa, tornando-se urgente, portanto, a sua supressão. De acordo com a lei, as APPs devem ser essencialmente constituídas de espécies nativas.

Tabela 1. Áreas necessárias para o cumprimento das exigências do Código Florestal no imóvel rural denominado Taquaruçu

\begin{tabular}{lccccc}
\hline & Área total & $\begin{array}{c}\text { APP } \\
\text { existente }\end{array}$ & $\begin{array}{c}\text { APP a } \\
\text { recuperar }\end{array}$ & $\begin{array}{c}\text { Área } \\
\text { disponível } \\
\text { para RL }\end{array}$ & $\begin{array}{c}\text { Área de RL } \\
\text { a recuperar }\end{array}$ \\
Hectares & 264,96 & 31,16 & 5,73 & 40,00 & 12,99 \\
Porcentagem & 100 & 11,8 & 2,2 & 15,1 & 4,9 \\
\hline
\end{tabular}

APP - Áreas de Preservação Permanente

$\mathrm{RL}$ - Reserva Legal

Além das áreas definidas como APPs, foram mapeados outros 40 ha de vegetação nativa na forma de florestas secundárias em estágios médios e avançados de sucessão ecológica, os quais podem ser averbados como Reserva Legal (RL). Dentre tais remanescentes de vegetação nativa, 25,01 ha (63\%) ocupam áreas com menor potencial agrícola, incluindo áreas com baixa fertilidade natural, drenagem deficiente, solos rasos e/ou declividade acentuada. Para contemplar os necessários $20 \%$ da área, devem ser acrescentados outros 12,99 ha de áreas a serem recuperadas.

Para definição de RL na abordagem de maximização do potencial agrícola, foram incluídas essencialmente, áreas localizadas em classes com maior declividade (entre 15 a 70\%) e mantidas glebas contínuas de áreas cultivadas para minimizar manobras com o maquinário agrícola. As características dos solos nas áreas definidas como RL também seguiram condições agronomicamente mais interessantes, ocupando áreas mais dissecadas, localizadas na porção inferior das encostas, ao longo da rede de drenagem, como pode ser observado na Figura 1.

Sugeriu-se, também, nesta interpretação, a realocação de elementos de floresta insular (capões de mata) localizados em áreas com maior aptidão agrícola, isto é, sugere-se a 


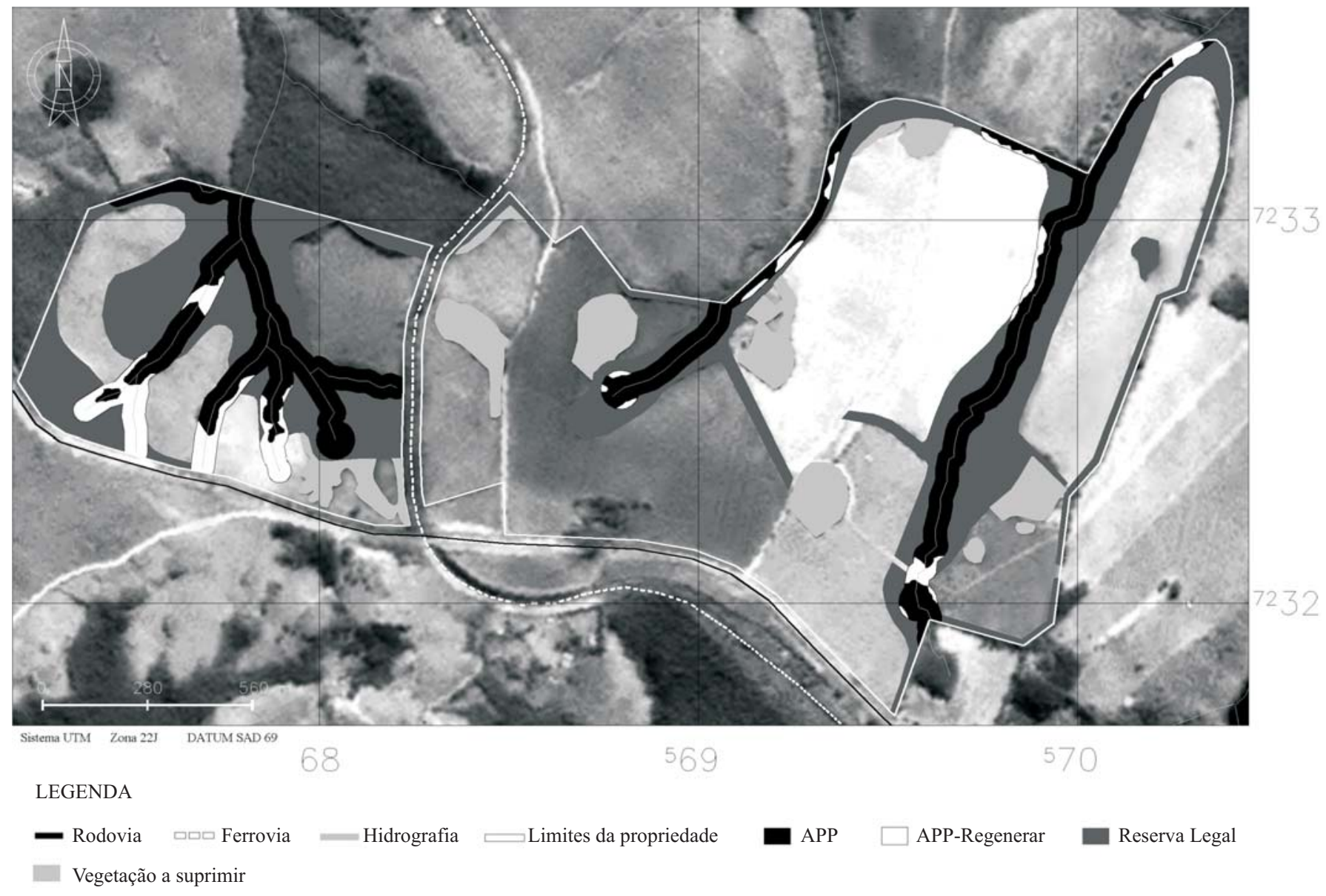

Figura 1. Adequação ao Código Florestal e alocação de Reserva Legal (RL) segundo perspectiva produtivista

supressão de algumas áreas isoladas com formações florestais, totalizando 14,99 ha (37\% das áreas disponíveis para averbação). Como contrapartida, propõe-se a recuperação de áreas equivalentes, localizadas em áreas com menor potencial produtivo e, portanto, mais suscetíveis à degradação, pelo uso intensivo.

Um inconveniente desta proposta é que, antes do corte dessas áreas para uso agrícola, as áreas definidas como RL precisam ser recuperadas. Este processo acarreta custos e, mesmo com intervenção antrópica, demandará tempo considerável. Somente após a recuperação dessas áreas e autorização do órgão competente é que esses capões poderão ser manejados. Faz-se necessário, então, a recuperação de 27,98 ha, o que acarretará em um déficit de área agrícola de 14,99 ha no período oportuno para a recuperação.

Analisou-se na segunda abordagem, o contexto, para a conservação da natureza nas bacias hidrográficas na qual a propriedade está inserida, já que os processos naturais e antrópicos exercem forte influência nos processos ecológicos e na dinâmica hidrológica. Como a propriedade de estudo está localizada ao longo do divisor de águas entre três microbacias e se considerando conceitos de biologia da conservação, relativos à formação dos corredores ecológicos, a conexão entre estas é considerada de suma importância.

O problema para conexão dessas microbacias está relacionado ao fato de que elas estão divididas por duas grandes barreiras antrópicas, localizadas ao longo dos divisores d’água, em que a primeira barreira, de maior importância, é a BR 376, rodovia com tráfego intenso e fluxo constante de veículos; a segunda se refere a uma ferrovia com fluxo intermitente e menos intensivo de composições. Em relação à rodovia, optou-se por não propiciar a conexão das RLs com a microbacia situada ao sul da propriedade, para evitar o tráfego de animais silvestres na rodovia por se tratar de área de grande risco.

As microbacias situadas a noroeste (microbacia 1) e a nordeste (microbacia 2) conforme demonstrado na Figura 2, estão divididas pela ferrovia que também separa a propriedade. Nesta abordagem com caráter conservacionista, preferiu-se a conexão das áreas de RL e APP entre as duas bacias, pois, embora exista a barreira ferroviária, ela apresenta menores riscos para a fauna silvestre, em função do fluxo intermitente e menos intenso de composições.

Como pode ser observado na Figura 3, foram mantidos os capões de mata existentes, devido à sua importância como habitats para espécies diversas, conectando-os com as APPs e ao longo das duas microbacias. O montante de 14,99 ha a serem recuperados foi utilizado nas sugestões de ligação dos fragmentos de floresta, com o propósito da formação dos corredores e no entorno de áreas degradadas em princípio de voçorocamento.

Embora a largura desses corredores não contemple as 


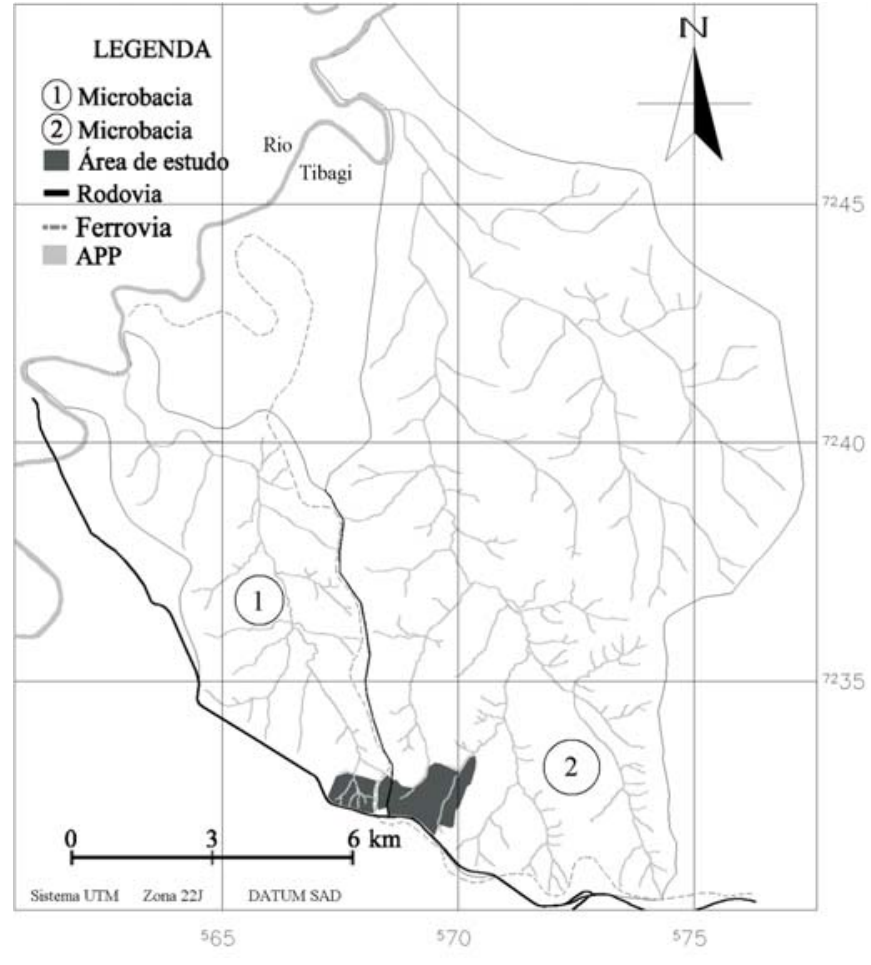

Figura 2. Microbacias hidrográficas nas quais se insere a área de estudo necessidades de algumas espécies com maior demanda, territorial, as vantagens ecológicas e ambientais desta prática são evidentes. A largura dos corredores é influenciada pelos efeitos de borda e por perturbações antrópicas no seu entorno mas sua influência depende também do comportamento, do tamanho da espécie e de sua mobilidade e forma de dispersão (Mauro et al., 2003).

Em relação à análise morfométrica das microbacias, os valores encontrados para o índice de compacidade, foram: microbacia $1 \mathrm{Kc}=1,57$, e microbacia $2 \mathrm{Kc}=1,34$. Para a ordem dos cursos d'água encontrou-se, para a microbacia 1 Oc $=3^{\circ}$ e para a microbacia 2 Oc $=4^{\circ}$. Na densidade de drenagem chegou-se aos valores de 1,48 $\mathrm{km} \mathrm{km}^{-2}$ e 1,40 km km-2 para as microbacias 1 e 2 , respectivamente; esses valores por sua vez, indicam que a microbacia hidrográfica 1 é mais estreita e alongada e apresenta maior densidade de drenagem por quilômetro quadrado, o que permite concluir que é mais dissecada, apresentando superfícies planas menos evidentes e declividade mais acentuada em função do controle geológico, com predominância de rochas sedimentares psamíticas do Grupo Itararé.

A microbacia 2, por ser mais arredondada, pode apresentar problemas, como alagamento nos pontos de afluência dos cursos nos momentos de chuvas torrenciais, pois há concentração de grandes volumes d’água com baixa velocidade de-

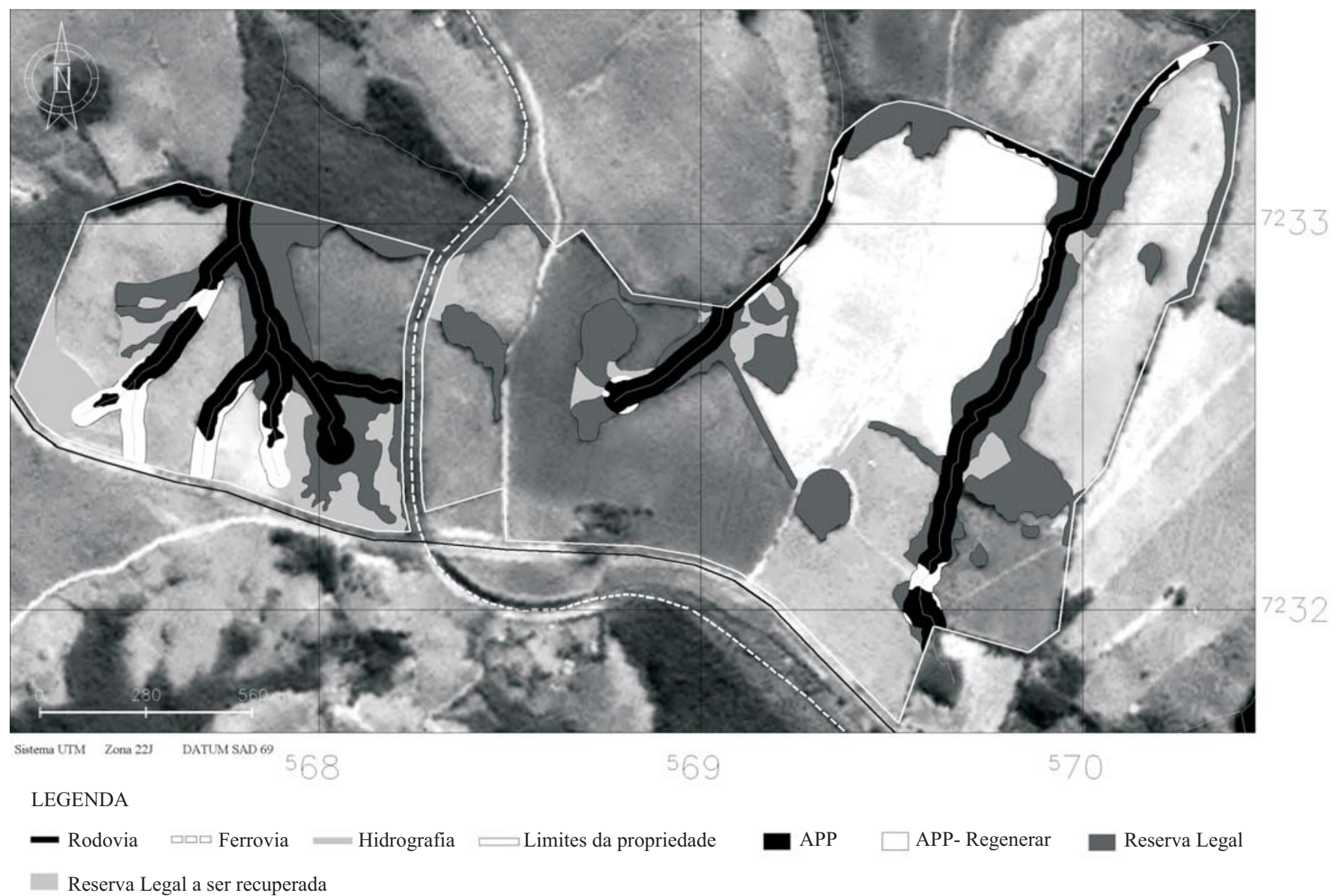

Figura 3. Adequação ao Código Florestal e alocação de Reserva Legal (RL) segundo perspectiva conservacionista 
vido a menores inclinações do leito da drenagem principal e saída estreita da microbacia. Nessas áreas, onde predominam rochas sedimentares com textura mais fina, derivadas da formação Ponta Grossa, faz-se importante priorizar e facilitar os processos de infiltração e escoamento base.

A ordem dos cursos d'água apresentou-se maior para a microbacia 2 em virtude desta ser 3,8 vezes maior que a microbacia 1; esses valores mostram que a referida microbacia é mais suscetível ao manejo, devendo-se priorizar a sua conservação com a alocação da RL, fato este que pode ser visualizado na proposta da Figura 3, a qual sugere a maior parte das áreas de RL a serem recuperadas na microbacia 1.

Embora o Código Florestal Brasileiro possa ser considerado avançado ao reconhecer as florestas e as demais formas de vegetação como bem de interesse comum a todos os habitantes do país, a sua aplicação, em particular a definição de áreas de alocação para Reserva Legal, permite ampla subjetividade. Pode-se sugerir diferentes localizações para a Reserva Legal em uma propriedade rural, em função de aspectos e interesses distintos, haja visto que esta legislação possibilita a mitigação de impactos ambientais não especificando, no entanto, de modo objetivo, conceitos considerados fundamentais para a conservação, como conectividade em relação às bacias hidrográficas, largura de corredores, tamanhos de fragmentos e as conseqüências ecológicas do efeito de borda. O conjunto de medidas adotadas nos âmbitos federal e estadual, constitui o arcabouço legal para garantir a conservação de áreas significativas através da implantação de sistemas de áreas protegidas integrados em múltiplas escalas geográficas, através de corredores da biodiversidade.

Para maximizar este potencial, faz-se necessário, portanto, a adoção de estratégias de planejamento territorial que priorizem o desenvolvimento de sistemas integrados de áreas protegidas, incluindo-se as RLs, APPs e Unidades de Conservação. Neste sentido, evidencia-se o potencial para o planejamento integrado de bacias hidrográficas, com o objetivo de priorizar áreas para conservação e averbação de Reservas Legais, tanto para os imóveis na qual estão localizadas, como RL compensatória para outras propriedades nas quais se faz necessário a sua recuperação, conforme o previsto na legislação.

\section{CONCLUSÕES}

1. A legislação pode contribuir para mitigar impactos não contemplando, porém, conceitos importantes para o planejamento territorial e conservação da natureza.

2. Pela subjetividade existente e necessária na legislação ambiental, é possível contemplá-la de várias maneiras, muitas das quais com enfoque menos conservacionista do que o esperado ou necessário.

3. Neste caso, aumenta a importância dos órgãos fiscalizadores que podem evidenciar o potencial para o planejamento integrado de bacias hidrográficas com o objetivo de priorizar áreas para conservação e averbação de Reservas Legais.

\section{LITERATURA CITADA}

Brasil. Código Florestal Brasileiro. Lei Federal n.4.771, de 15 de setembro de 1965.

Brasil. Ministério da Agricultura. Programa Nacional de Microbacias Hidrográficas: manual operativo. Brasília, 1987. 60p.

IAP - Instituto Ambiental do Paraná. SISLEG - Sistema de manutenção, recuperação e proteção da reserva florestal legal e áreas de preservação permanente. http://www.pr.gov.br/meioambiente/iap/bio_sisleg_res.shtml. 21 Jun. 2005.

IBGE - Instituto de Brasileiro de Geografia e Estatística. Mapa de vegetação do Brasil. 2004.

Lepsch, I. F. Manual para levantamento utilitário do meio físico e classificação de terras no sistema de capacidade de uso. In: Lepsch; I. F. Bellinazzi Jr.; R. Bertolini; D. Espínola, C. R. $4^{\mathrm{a}}$ aproximação. Campinas: SBCS. 1983. 175p.

Marouelli, R. P. O. Desenvolvimento sustentável da agricultura no cerrado brasileiro. Brasília: ISAEFGV/ Ecobusiness School, 2003. 54p. Monografia

Mauro, R. A.; Silva, M. P.; Delorme, J. P.; Santos, J. C. C. Corredores ecológicos e atividades agropecuárias: A conservação em áreas particulares. In: Áreas protegidas: Conservação no âmbito do Cone Sul. Pelotas: Alex Bager, 2003. 22p.

Odum, E. Ecologia. Rio de Janeiro: Guanabara S.A., 1988. 434p.

Paccagnella, L. H.; Senô, M. A. A. F. Normas jurídicas relativas a área de preservação permanente e reserva florestal legal. In: Manejo e recuperação florestal: legislação, uso da água e sistemas agroflorestais. Jaboticabal: FUNEP, 2003. 180p.

Paraná. Lei $n^{\circ} 11.054$ de 11 de janeiro de 1995. Dispõe sobre a Lei Florestal do Estado. http://celepar7cta.pr.gov.br/ SEEG/sumulas.nsf/9973229f063f4a8d03256c2f007a992a/ 1cb43702c546d1d003256e99006648c6?OpenDocument. 18 Abr. 2007.

Paraná. Decreto n 387 de 03 de março de 1999. Dispõe sobre a instituição do Sistema de Manutenção, Recuperação e Proteção da Reserva Florestal Legal e Áreas de Preservação Permanente, integrado ao programa de conservação da biodiversidade, Sistema Estadual de Reposição Florestal Obrigatória, Programa estadual de desenvolvimento florestal e programa florestas Municipais. http://www.pr.gov.br /meioambiente/ iap/index.shtml. 20 Nov. 2005.

Paraná. Decreto nº 3320, de 12 de julho de 2004a. aprova os critérios, normas procedimentos e conceitos aplicáveis ao SISLEG. http://www.pr.gov.br /meioambiente/iap/index.shtml. 20 Nov. 2005.

Paraná. Portaria IAP nº 233, de 26 de novembro de 2004b. Aprova os mecanismos de operacionalização aplicáveis ao SISLEG. http://www.pr.gov.br/meioambiente/iap/ index.shtml. 20 Nov. 2005.

SEMA - Secretaria de Estado do Meio Ambiente e Recursos Hídricos, Secretaria de Estado de Esportes e Turismo, Sociedade Protetora da Vida Selvagem, Secretaria de Estado da Cultura. Diretrizes para uma política estadual de ecoturismo. Curitiba 1996. http://milenio.com.br/ilhas/Diretrizes-IAP.doc. 28 Nov. 2005

Valente, O. F.; Gomes, M. A. Conservação de nascentes: hidrografia e manejo de bacias hidrográficas de cabeceiras. Viçosa: Aprenda Fácil, 2005. 210p. 